This is the post-peer reviewed final draft version of the following article: Heeks, R. ICT4D2.0: the next phase of applying ICT for international development, IEEE Computer, 41(6), 26-33, 2008, which has been published in final form at: http://ieeexplore.ieee.org/xpl/articleDetails.jsp?arnumber=4548169

\title{
ICT4D 2.0: The Next Phase of Applying ICTs for International Development
}

\author{
Richard Heeks \\ Development Informatics Group \\ University of Manchester, UK
}

We are moving to a new phase in ICT4D - the application of information and communication technologies for international development. This new phase presents new opportunities for informatics professionals, and new markets for ICT vendors. It also brings new challenges to our established methods of working, and the need for new expertise and new worldviews. These must be understood if we are to harness digital technologies in the service of some of our world's most severe problems.

In this article, I will chart this phase change - from "ICT4D 1.0" to "ICT4D 2.0" and its implications. The following section outlines the background to these phases, charting the logic and chronology of applying ICTs in developing countries. The implications of the phase change are then charted. First, in terms of new technology priorities. Then, in relation to the new models of innovation we may need to embrace. Finally, in terms of the new worldviews that may guide our thinking in this field.

\section{Why ICT4D?}

Before proceeding, though, we should ask "why ICT4D"? Why should we give any priority to ICT application for the poor in developing countries? There is a moral argument. Most informatics professionals spend their lives serving the needs of the world's wealthier corporations and individuals - to borrow bank robber Willie Sutton's phrase - "because that's where the money is". Yet seeking to squeeze a few extra ounces of productivity from firms that already perform relatively well, or save a few minutes in the life of a busy citizen pales in ethical importance compared to applying new technology to the mega-problems of the planet.

It is the poor of the world who are on the front-line of those problems. From climate change to conflict and terror; from disease to resource depletion - it is the poor in developing countries who suffer most. And, of course, they suffer from that other blot on the world's conscience - poverty - with more than half the global population living on less than two US dollars per day.

There is enlightened self-interest. In a globalised world, the problems of the poor today can - through migration, terrorism, disease epidemics - become the problems of those at the top of the pyramid tomorrow. Conversely, as the poor get richer, they buy more of the goods and services that industrialised countries produce, ensuring a benefit to all from poverty reduction. 
And there is personal self-interest. Compare designing a system for an African or Asian community to doing the same for a company in the global North. The former is quite simply more interesting - a richer, more satisfying, more colourful experience.

That answers the "why 4D" component but what about the "why ICT" half? Why invest in digital technologies rather than, say, a tubewell to allow access to water? The standard response is "we need to invest in both - development requires water and information." A more assertive response might give a macro-level answer.

Economic, social and political life in the $21^{\text {st }}$ century will be increasingly digital, and those without ICTs will be increasingly excluded. And it might give a micro-level answer. Ask poor communities or look at how they spend what little money they have - not always, but sometimes, they prioritise the ICT option.

\section{From ICT4D 1.0 to ICT4D 2.0}

The first digital computer put to use in a developing country was installed in Kolkata in 1956 at the Indian Institute of Statistics for scientific calculation work. From that early start until the 1990s, there were two application emphases in the use of computing for development. Initially, government was the key actor, and IT (as it then was, rather than ICT) was applied mainly to internal administrative functions of the public sector in developing countries. During the 1980s, the multinationals and other firms came to the fore, and IT was seen as a tool for delivery of economic growth in the private sector. We might thus christen this "ICT4D 0.0" period IT4G information technology for government; then overtaken by information technology for growth.

Two things happened in the 1990s that gave birth to what might recognisably be called ICT4D 1.0. The first was the Internet. The second was the Millennium Development Goals (MDGs).

The Internet sparked a generalised upsurge of interest in ICTs, including a reinvigorated interest in how ICTs might be applied in developing countries. At the same time, international development began to move back up the political agenda. This move was given impetus by the search for concrete targets; emerging first as the International Development Goals in 1996, and then formalised as the MDGs by the September 2000 Millennium Declaration which sought particularly to reduce poverty, and improve health and education and gender equality.

The digital technologies of the 1990s, then, were a new tool in search of a purpose. Development goals were new targets in search of a delivery mechanism. That these two domains should then find each other was not unexpected. They gave rise to ICT4D in flurry of publications, bodies, events, programmes and project funding: the 1998 World Development Report from the World Bank, highlighting the role of information, knowledge and ICTs in development; the creation by the G8 countries of the Digital Opportunities TaskForce in 2000, setting an agenda for action on ICT4D; and the World Summits on the Information Society held in Geneva in 2003 and Tunis in 2005, acting as key learning and policy-formation points along the ICT4D path. 
The key actors became international development organisations and NGOs (nongovernmental organisations); and the priority application of ICTs was to the MDGs. Centrally, the MDGs are about improving the lives of what Prahalad has called the "bottom of the pyramid": the four billion majority on the planet who live on an average of less than US\$2 per day.

\section{What Happened During ICT4D 1.0?}

With timescales short and pressure to show tangible delivery, the development actors involved with ICT4D did what everyone does in such circumstances. They looked around for a quick, off-the-shelf solution that could be replicated in poor communities in developing countries.

Given that most poverty is located in rural areas, the model that fell into everyone's lap was the rural telecottage or telecentre which had been rolled-out in the European and North American periphery during the 1980s and early 1990s. Seen to mean a room or building with one or more Internet-connected PCs, this could be installed fairly quickly; could provide tangible evidence of achievement; could deliver information, communication and services to poor communities (and could provide sales for the ICT companies who were partners in most ICT4D forums). Thus a host of colourfully-named projects began rolling out from InforCauca in Colombia to CLICs in Mali to Gyandoot in India.

Naturally, ICT4D 1.0 was not solely restricted to telecentre projects. But the telecentre was the archetype for this period, stretching from the mid/late-1990s to the $\mathrm{mid} / \mathrm{late}-2000 \mathrm{~s}$.

And what has been the outcome? Painting with a broad brush, we can sum up with three words: failure, restriction, and anecdote. Each of these has led to specific lessons and new watchwords:

- Sustainability: given the failure of many ICT4D projects to deliver and/or survive, there is a new emphasis on ensuring the longevity of such projects.

- Scalability: given the limited reach of individual telecentre projects, there is a new search for scalable ICT4D solutions.

- Evaluation: given that ICT4D 1.0 was often held aloft by hype and uncorroborated stories, there is a new interest in objective evaluation of impacts.

But, more generally, these outcomes of the first decade of ICT4D have led to a rolling re-appraisal of priorities, processes, and purposes. There is no sharp divide to mark out the first from the second phase of ICT4D - the latter began as the first lessons were being learned back in the $20^{\text {th }}$ century. And there is no consensus on what ICT4D 2.0 looks like - that is an ongoing discussion.

Nonetheless, we can sketch out some of its component parts; a task that will be taken up in the rest of this article. 


\section{ICT4D 2.0's New Technological and Application Priorities}

As we stand on the threshold of ICT4D 2.0, the key technical question to be answered currently appears to be: "How will we deliver the Internet to the remaining five billion?"

Back in the 1990s, the initial model was that which was serving the global North: a PC connected via a landline. But attempted roll-out faced major hurdles as the South's bottom of the pyramid proved far harder to reach. The model was too costly to be sustainable or scalable. And/or the necessary power and telecommunications foundations were often absent. Pushing forward the Internet-connected PC will therefore require hardware innovations in:

- Terminals: there are ongoing efforts to develop the type of low-spec, low-cost, robust terminal device that could work in large numbers of poor communities. The most high-profile of these is the One Laptop per Child project's XO and, not coincidentally, a slew of relatively-similar devices is spewing forth. Some - like the PixelQi and the Intel Classmate - have a similar intention to target developing country needs. Others - Linutop, InkMedia, Elonex ONE, Asus Eee and many more - are more generalised commercial products. Despite twenty years of overpromising and underdelivering - from the "People's PC" to the Simputer - it seems low-cost terminals will be a central part of ICT4D 2.0.

- Telecommunications: wireless has become the delivery mode of choice to provide connectivity into poor communities in the global South. Interest in satellite-based forms such as VSAT during the 1980s and 1990s has given way to a focus on land-based transmission systems. In the same way, attention is turning from WiFi-based systems and innovation to WiMAX. The overriding innovation issue remains the relatively low traffic demand and low population density of most areas of rural poverty; requiring solutions that can deliver broader reach at lower cost than current technology.

- Power: with only 15 percent of rural households in sub-Saharan Africa having access to electricity ${ }^{1}$, three areas of innovation continue to be required that take us through the power cycle - new, low-cost devices for local electricity generation; better ways to store, carry and transmit electricity; and lower power consumption by ICT devices.

But, in some ways, we stand at a fork in the Internet access road. Do we still keep pushing down the PC-based route when less than 0.5 per cent of African villages have so far got a link this way ${ }^{2}$ ? Or do we jump ship to a technology that has already reached many poor communities - mobile telephony - which, for example, already reaches out to more than half the African population ${ }^{3}$ ? Here the requirement for hardware innovations appears to be relatively limited. At least, one can say that to date the mobile phone offerings from multinational firms appear to be diffusing fairly readily. Half the world's population - stretching well down into the bottom of the pyramid - are mobile phone users; a greater number have access to a mobile; and growth rates are currently fastest in the poorest regions.

Current growth rates will likely carry usage to well over $90 \%$ of the world's population ${ }^{4}$, leaving the questions as those of reaching the last half-billion, and of the spread of Internet-enabled phones, given that most phones in poor communities are currently calls-and-SMS-only. For both these questions, the need for hardware 
innovation may re-emerge. There are also likely to be innovations as "bottom-up" developments on mobiles converge with "top-down" attempts to produce lower-cost PC-like terminal devices; ending with something like a "Blackberry-fordevelopment".

Finally, in dealing with the "remaining five billion" issue, some have asked whether the Internet should be the focus. Or, should we look at where the poor have "voted with their wallets" and see whether the simpler, cheaper technologies already in use can deliver sufficient ICT functionality to make a difference. Rather than wait for handset and bandwidth upgrades to allow mobile Internet access, what can be achieved for development through calls and SMS? And what about older technologies? Access (as opposed to ownership or geographical coverage) figures are hard to come by, but we can estimate that something like $80 \%$ of the population in developing countries has access to a radio, and $50 \%$ to a television ${ }^{56}$. Hence, early in ICT4D's history, the swift reinterpretation of "ICTs" to incorporate radio and television.

And hence, too, the role that convergence will play in ICT4D 2.0. In practice, this means looking at the technologies that already penetrate - mobiles, radios, televisions - and seeking ways to add computing and Internet functionality. Pilot projects are already underway. Community radio stations seek answers to listener questions via email and the Web, and broadcast the response. Telecentre databases add an SMS gateway that allows farmer searches in the field via mobile phone. Many other such hub-and-spoke innovations are likely to find a valuable application in future.

\section{New Applications}

Moving outwards from the hardware core of ICT4D, we next meet an issue that has been alive since at least the 1960 s - that of interface design for development. It is a common mistake to equate the poor in developing countries with illiteracy. Yet adult literacy even in the very poorest countries of the world is still greater than 50 percent, and two-thirds of 15-24 year olds are literate ${ }^{7}$. Effectively, every community will have at least some literate members who can act as "infomediaries", thus massively multiplying the accessibility of written materials, online or otherwise. And literacy rates among the poor are steadily rising.

Nonetheless, interface innovation is still needed to drive access to ICT-based information, services and jobs. First, in the field of audio-visual interfaces. Second, though now covered for all the world's major languages, there is still some work to be done to create interfaces for all local languages.

Even if past and future innovations can provide access to ICTs for the majority world, the hardware-plus-interface combination remains an empty husk. When filled with applications software, that husk can have four main development roles: data content handler, interactive communicator, service deliverer, and productive tool. These form a sort of chronology as ICT4D has moved slowly towards closing the gap between supply (what is easy to provide) and demand (what the bottom of the pyramid actually wants).

Content. It was rapidly recognised during ICT4D 1.0 that plugging a peasant farmer or slum-dweller into Google was of limited value. Much of information they required 
would not emerge because it was not present in digital format. Hence, a series of projects, such as Open Knowledge Network, seeking to create relevant local data content focused on livelihood-appropriate issues such as health, education, agriculture, and rights. Hence, too, a recognition once media technologies like radio and television were incorporated into ICT4D, that their non-interactive and broadscale nature presented a problem of lack of specific data relevance. For these technologies, the phase change to ICT4D 2.0 is therefore associated with "community radio" - very localised broadcasting that allows community input. "Community television" is not a realistic prospect but its equivalent is participatory video - the creation of video content by the local community and its presentation at individual screenings for community groups.

Interaction. There was quite a fuss made in this domain about dealing with ICT not IT i.e. technology "now with added C". Despite this, use of technology for communication - at least, for interactive communication - has been a late arrival. This may be because, faced with the telecentre model, interaction meant email, and the poor had no-one to message. Their social networks were seen as small, local and informal. In fact, as take-up of mobile phones proved, these networks have been extended by rural-to-urban and international migration. And they might be extended further by the new technology, thus adding to the "social capital" of the marginalised majority. How this can be done, and how the interactive communications capabilities of digital media can best be exploited, remains a growing task for ICT4D 2.0.

Services. Just as Web models move from informational to interactional to transactional stages, so ICT4D has recently moved to look at service delivery for the poor. To date, this has targeted e-government: enabling bill payments via telecentres, or helping order important certificates. The limited reach of the telecentre model constrains the impact of such innovations and ICT4D 2.0 seems more likely to take forward "m-development": finding ways to hang relevant services onto the growing mobile base. For the moment, this means exploiting existing functionality such as use of SMS for tasks ranging from reminding people living with AIDS to take their antiretrovirals, to monitoring elections. From here forwards, it means adding further functionality, such as "banking the unbanked": using mobiles to deliver financial and banking services to those currently excluded from the mainstream.

Production. ICTs seem well understood as tools for delivering information and services to the world's poor. Where they have so far been little understood is as tools the poor can use to create new incomes and new jobs. This new productive view is partly encompassed when the poor act as authors of data content; as seen in community radio and participatory video projects. As well as delivering relevant content, these also empower by making those involved into participative creators; able to take control of these means of production for the $21^{\text {st }}$ century. Can this now spread further to encompass all of Web 2.0 - can bloggers, and mashers, and wiki-writers be drawn from the ranks of the world's most disadvantaged? And will this require new applications to achieve?

The sense of empowerment and inclusion that come from content creation are valuable. But the no. 1 priority for the poor is typically income and employment. Here we are only just waking up to the possibilities. Mobiles are widespread. To date the poor have created incomes both around the technology - selling accessories; 
selling pre-pay cards - and via the technology - selling or taking calls. But are there novel ICT-enabled microenterprises that could be developed? This is already happening around some rural and urban telecentres with "social outsourcing": the outsourcing of IT services to social enterprises based in poor communities ${ }^{8}$. But a priority for ICT4D 2.0 will be conceiving new applications and new business models that can use the growing ICT base - of mobiles, of telecentres, and so forth - to create employment.

\section{ICT4D 2.0's New Innovation Models}

Underlying the discussion above are two different views about technology and development - or, at least, two extremes on a continuum. At one end we have the "passive diffusion" view. Taking the lead from mobile telephony's rapid spread, this says that if ICTs do have a developmental value for the poor, then a combination of private firms' search for profit plus the poor's search for value will make it happen. Any attempt to intervene from outside is foolish and wasteful: a force-feeding of the inappropriate that will only lead to messy regurgitation. Conversely, the "active innovation" perspective feels the market will not deliver - or will deliver too slowly to the poor. Hence, intervention is required; intervention in the form of new innovations that will better help to meet development goals.

This paper will not compare these views in any detail. Certainly active innovation took a knock during ICT4D 1.0. There is a sense that international donor agencies subsidised the unsustainable, and were footling around in the supply-driven telecentre pond, oblivious to the market-driven mobile tsunami around them. On the other hand, non-market interventions have been the root of many subsequently marketised technologies. From the first computers to the origins of the Internet to the competitors spawned by the OLPC XO, active innovation has often been the foundation for passive diffusion. Finally, the two perspectives converge when private firms take the bottom of the pyramid notion to heart and start designing products specifically with poor consumers in mind.

What we can conclude is that some element of active innovation is likely to remain in the ICT4D field. In that case, two key questions ensue.

First, what to innovate. As the OLPC experience demonstrates, large-scale hardware and operating system innovations specifically targeted at the bottom of the pyramid are risky ventures, only for the very brave or the very foolish. In a moderated way, that even applies to the large private sector players. Instead, most ICT4D 2.0 innovation looks likely to occur on a smaller scale either in adapting or in applying existing technologies. Put another way, innovation appears more feasible as one moves up the chain from new infrastructure (telecoms, power) to new hardware to new software to new data content to new business models and processes.

Second, how to innovate. In terms of the innovation process, we can educe three different modes, here labelled pro-poor, para-poor, and per-poor:

Pro-poor innovation is that done outside of poor communities but on behalf of the poor. Telecentres began this way and the OLPC was largely designed this way. This 
can be an effective approach for engaging resources from the global North in developing country problems. However, it runs into the danger of "design-reality gaps": a mismatch between the assumptions and requirements built into the design, and the on-the-ground realities of poor communities.

The jury is still out on whether the various low-cost terminal devices will fall into this gap trap. But initial telecentre models surely did. And when there's a large designreality gap, the outcome is almost certain failure ${ }^{9}$. Hence, the widespread lack of success and sustainability reported for telecentre projects. Nonetheless, there will still be a space for pro-poor innovation in ICT4D 2.0. For example, innovative pro-poor pricing models have worked. Pre-paid for mobiles has been an essential part of their uptake in the developing world, and no doubt Microsoft's US\$3 Student Innovation Suite software package for developing countries will also prove popular.

Para-poor innovation is that done working alongside poor communities. Its use has grown during ICT4D 1.0 and it will be central to ICT4D 2.0. The need for participative, user-engaged design processes was a key learning point of the first phase. It's a lesson the informatics discipline generally learnt several decades ago, but there is always a need to reinvent such wheels when new application areas arise, filled as they are by a goldrush of new actors.

Being learnt more slowly - though recognised in development studies in the 1990s is the lesson that community participation in project design is fraught with pitfalls. Who participates matters - often a very small, vocal, elite minority. How they participate matters - individual and group processes produce different results. And why they participate matters - participants often give the answers they think the designers want to hear. The very nature of ICT4D participation is also difficult because it requires multiple divides between designer and user to be bridged: techie vs. non-techie; rich vs. poor; often Western vs. non-Western mindset. And for certain projects, urban vs. rural; men vs. women.

Per-poor innovation is innovation by and within poor communities. In the 1990s, it was hardly a possibility - there was insufficient contact between poor users and the new technologies; old information technologies like radio and TV provided no innovative space. But this has changed in the last few years. As mobiles have arrived, and as PCs and the Web start to arrive, the poor have themselves become innovators. Not in the traditional laboratory/R\&D sense of the term. But in the sense of adapting and applying the technology in new ways.

By and large we have only anecdotes to date about:

- New processes e.g. beeping (or flashing) that allows a message to be communicated without the call being completed. Street vendors use this to receive free "I want to buy now" messages from known customers.

- New business models e.g. use of airtime as currency has allowed mobile phones to metamorphose into mobile wallets. Those who own phones in poor communities have therefore been able to use them for payments or for receipt of remittances from distant relatives.

- New products e.g. back-street rechipping of phones. Informal-sector enterprises are emerging that strip and resell the circuitry from high-end phones, replacing it with basic calls-and-SMS-only functionality. They then sell the resulting high- 
end-body-with-low-end-organs as a unique hybrid for those who want the latest look but lack the budget to match.

As the weight of such anecdotes grows, there will be pressure within ICT4D 2.0 for more systematic means to "harvest" per-poor innovations. This is something wellpractised within the appropriate technology movement. This movement has already been through its cascade from pro- to para- to per-poor innovation, and has evolved methods for capture and scaling of new ideas from poor communities. Such methods may arguably be enhanced during ICT4D 2.0 by adding features from open source and Web 2.0 innovation models.

\section{ICT4D 2.0's New Worldviews for Action}

The key actors in the ICT4D field are drawn from particular disciplinary worldviews. What can we learn by looking at their backgrounds?

Many of those active in the field draw from a computer science background. Some from what we might call the "harder" end dealing with hardware and firmware, some from the somewhat "softer" ground of human - computer interaction. Such expertise is, of course, essential to ICT4D 2.0. It will be essential to delivering the new technological and application priorities detailed above. It will be an essential part of pro- and para-poor innovation.

But, alone, it is not enough. And, where it stands alone, problems arise. The root of a number of ICT4D failures is identified as their techno-centric approach, dominated by an informatics view of the world ${ }^{10}$. Such projects are frequently analogous with the old medical joke, "The operation was a success but unfortunately the patient died". They deliver a system that works technically but which fails to make a developmental contribution.

To move from the failures of ICT4D 1.0, then, we need to have new, broader worldviews guiding ICT4D 2.0 projects. But where will those broader worldviews come from? There are two main disciplinary candidates.

The first is information systems. During the 1980s and early 1990s, information systems was the intellectual home of ICT4D before it was called ICT4D; particularly within the work of IFIP's working group 9.4 on social implications of computers in developing countries. This has strengthened with the creation of IS discipline journals dealing solely with ICT4D; with new editorial board members on key IS journals being appointed with a specific developing country remit; and, most recently, with the Association for Information Systems' creation of a special interest group on IS in developing countries.

An information systems perspective offers the means to understand many of the problems that beset ICT4D projects. Most notably, it offers models for understanding the human, political, contextual reasons why so many ICT4D projects fail. And it offers approaches for addressing those factors during project design and implementation. At its widest setting, information systems also permits us to step 
right back and answer questions about the political economy of ICT4D: whose interests it promotes, and what its opportunity costs are.

But the information systems perspective falls down in two ways. It has at least in part lost track of the artefact, becoming so much of a social science and so concerned with context, that it fails to engage with the technology ${ }^{11}$. And it has made few connections with the context, stakeholders and process of development. Information systems tends neither to understand, nor to use the ideas of, development studies.

It is to development studies that we then turn. Development studies has so far failed to adequately conceive or support ICT4D. In part, this has happened because development studies turned away from technology generally in the 1980s; a counterreaction to the "big science" and "technology transfer" ideas that characterised the bythen-discredited paradigms that had dominated development in earlier decades.

As a result, ICT4D 1.0 grew as something of a bubble. It was driven on actors external to the development field, such as IT vendors, and by a few believers within that field. But it was isolated from the development mainstream who remained sceptical about technology, especially new technology (despite the fact that, in their own homes and workplaces, they increasingly relied on that technology).

As the 2000s progress, though, things are changing in development studies. Science and technology is moving back up the development agenda, driven by human development champions such as Jeffrey Sachs who see technology as central to achieving the MDGs; by the central importance given to science and technology by the NICs (newly-industrialised countries like Korea and Taiwan) and BRICs (Brazil, Russia, India, China) that are emerging as economic powers and as new aid donors; and by new perspectives on innovation that show how it can be effective in addressing the problems of the poor ${ }^{12}$.

There are thus greater opportunities within ICT4D 2.0 for engagement with development studies. This is an engagement that will help understand where digital technologies fit into development paradigms, processes and structures. Not only can this guide post-hoc activities like ICT4D impact assessment, it can also guide pre-hoc activities that seek to understand ICT4D priorities, and ICT4D project design and implementation good practice. A development studies perspective thus provides guidance at both a macro and micro level, all ultimately increasing the likely contribution of ICTs to development.

We can conclude, then, that each one of these three intellectual domains - computer science, information systems, development studies - has something to offer the ICT4D field.

Conceptually, this means we need spaces that bring these three domains together. That has not yet been achieved, and it remains the key intellectual challenge during ICT4D 2.0. But there are some promising possibilities in groupings such as the ICTD conferences, which get a mix of informatics professionals to address development issues, and in the proposed new IFIP grouping on computing-design-for-development. Both groupings focus those at the computer science/information systems boundary on the particular needs and practices of system design in a development context. They 
draw on the broader burgeoning fields of design-for-development in the academic sphere, and design-for-emerging-markets in the commercial sphere.

Practically, this means that ICT4D 2.0 projects need a combination of the three areas of expertise if they are to succeed. That could be interpreted as meaning multidisciplinary teams. But just as important will be the issue of leadership. Here, we can extend the general finding that successful IT projects are led by hybrids who span the technical and the organisational ${ }^{13}$.

\section{Figure 1: Creating ICT4D 2.0 Champions}

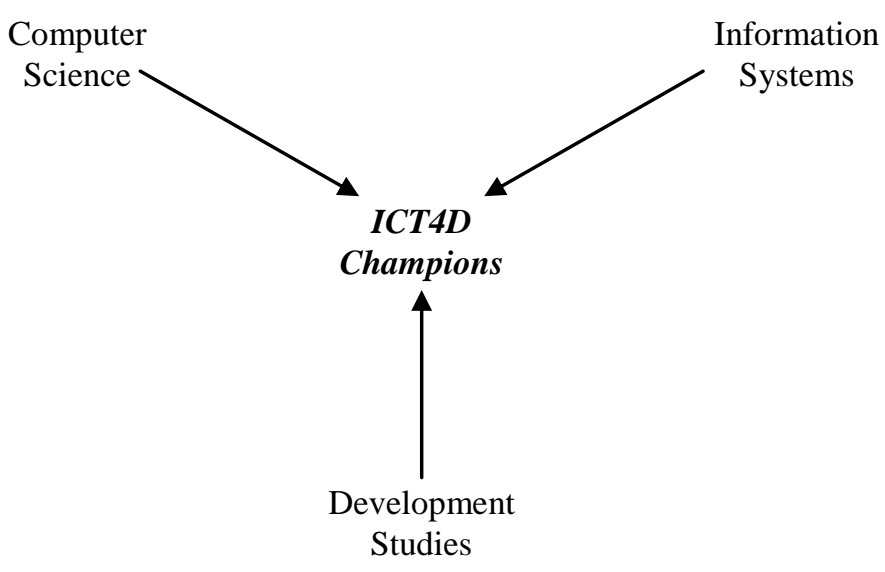

As summarised in Figure 1, we therefore need to develop or find ICT4D champions who are "tribrids". They must understand enough about the three domains of computer science, information systems, and development studies to draw key lessons and to interact with and manage domain professionals. How these tribrid ICT4D champions are created is another question. Vocational training will no doubt help; something that those creating Masters programmes in ICT4D are keenly aware of. The author also observes that tribrids tend to self-create during ICT4D projects as leaders from any individual domain rapidly find themselves facing problems that only insights from the other domains can solve. 
Strategically, it means that we also need to develop tribrids in ICT4D policy- and programme-making. We can chart this requirement by tracing a chronology of views about ICTs and development, as shown in Figure 2.

\section{Figure 2: Changing Views on ICTs and Development}

Perceived

Contribution of ICTs

to Development

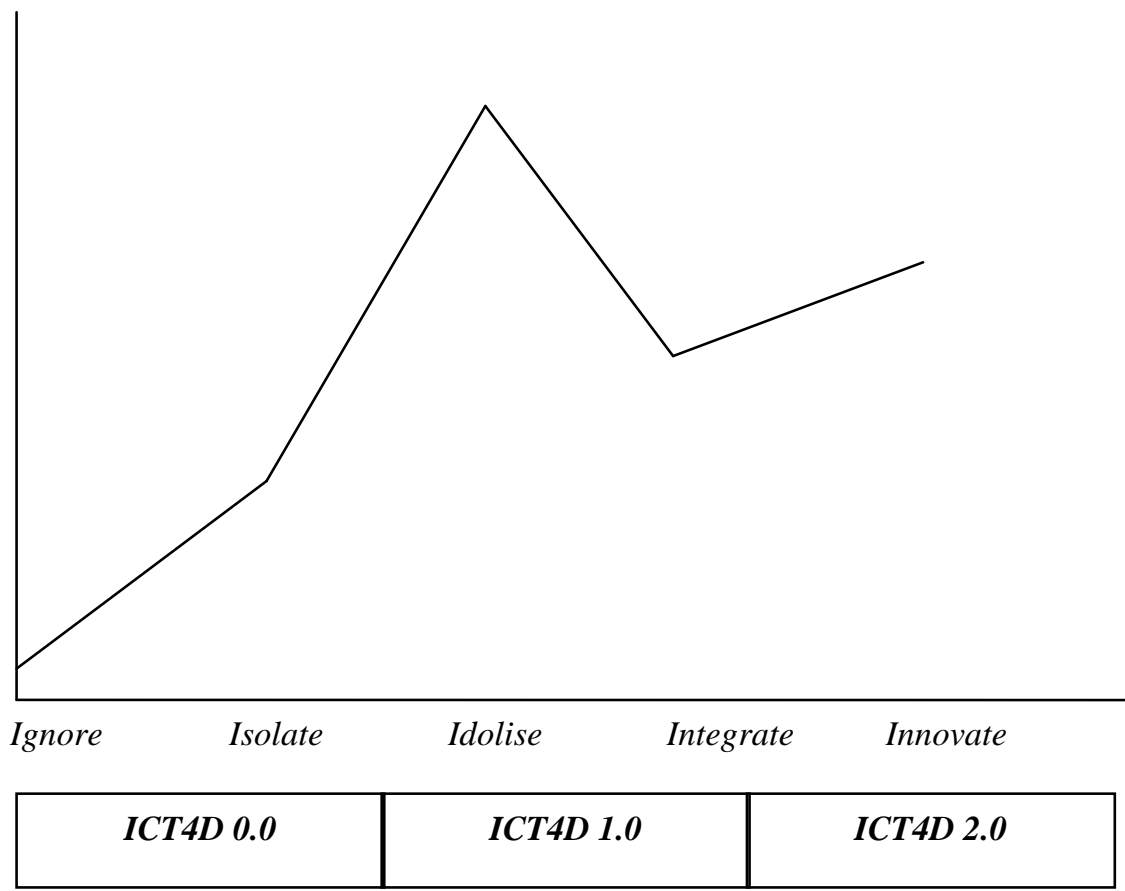

Differing Views on ICTs and Development

We can use this to reinterpret our earlier chronology of technology and development. Until the 1990s - what we labelled ICT4D 0.0 - most development policy- and programme-makers tended to either ignore IT (as it then was) completely, or to isolate it away from the mainstream of development into separate policies and ministries. Even if technology overall was seen positively within development studies paradigms which dominated thinking, IT was relegated to a more marginal role, or even seen negatively (as, for example, in the "Jobs not Computers" graffiti appearing in India during the 1980s).

As just indicated, this was a view that continued among at least some development officials during the 1990s as part of a more general side-lining of science and technology. But, at the same time, and driven from a technical and computer sciencebased paradigm that initially touched little on development studies, the ICT4D movement arose. This idolised digital technologies and placed them centre-stage in the development process.

ICT4D 1.0's failure to live up to its hype has already been charted, and the latter part of this phase has seen what might be called a reassertion of the supremacy of development studies, which has drawn also from information systems' views on what they see as the overly-narrow conceptions of computer science. ICT thus came to be "mainstreamed" within development, meaning it became subservient to the 
achievement of development goals, integrated into a long list of other tools and techniques that might prove useful. A typical formulation would start with a development goal; then seek to understand the role of information and communication in achieving that goal; then ask which new technologies - if any - could help deliver that role.

In many ways, this integrated approach looks very sensible. It represents where we start with ICT4D 2.0 and it lies behind mantras such as "a means not an end" or "a tool not a goal" that one hears quoted in relation to ICT4D.

But the integrated approach is also problematic for a number of reasons. By trapping ICT as a tool serving individual development goal silos, it misses out on ICTs' role as a cross-cutting, linking technology. This reduces the chance of diffusion of learning about ICTs, increasing the danger of reinventing wheels. ICTs can also now fall out of development programmes because they have no overarching champions. As many gender activists will tell you, when an issue becomes "mainstreamed" into development policy, that can be a synonym for "forgotten".

As described earlier, putting the ICT artefact front-and-centre in development is highly problematic. But it also achieves things that are lost when ICTs become subsumed through integration. A sense of excitement, motivation and hope about development are lost. And the ability to tap into additional development funding sources, such as those of IT sector philanthropists, can also be lost.

An integrated approach typically means an information-centric approach to ICTs, conceiving them as tools for handling the information and communication that development requires. As a result, it seems harder to recognise and develop ICTs' productive role as the potential basis for thousands of new ICT microenterprises. Finally, the transformative potential of ICTs disappears in an integrated approach. There is no question of seeing how ICTs could "move the development goalposts" or of "thinking outside the MDG box".

For an example, we need look no further than the current state of mobiles in development. There are no cross-cutting initiatives to learn about this new mass technology, which is only adventitiously being incorporated into development projects, or to identify its transformative possibilities. Where is the necessary MOTForce - a Mobile Opportunities Task Force to match the earlier DOTForce without which mobiles' contribution to development will be left to the market, left to chance, or just plain left behind?

Rectifying this during ICT4D 2.0 demands not just project-level tribrids, but policyand programme-level tribrids. They can provide a more balanced approach to ICT4D strategy; an innovative approach that pulls its plan of action from an amalgam of the key questions each domain can answer:

- What is possible with digital technology? (from computer science)

- What is feasible with digital technology? (from information systems)

- What is desirable with digital technology? (from development studies) 


\section{Summary}

There is no sharp dividing line to let us say, "ICT4D 1.0 stopped here; ICT4D 2.0 began here". On the ground, there is a sense of evolution, not discontinuity. And yet ... something messy, fuzzy but new is emerging. And it makes sense to see what happens if we give this a label.

What, then, might we argue are the key differences between ICT4D 1.0 and 2.0? In answering this and summarising what was presented above, we could draw on a number of parallels with the concept of Web 2.0. For example, ICT4D 2.0 is about the world's "long tail" - using digital technologies to draw on the capacities of the $80 \%$ who hold only $20 \%$ of the world's resources. Or, using Schmidt's "don't fight the Internet" characterisation, we can see ICT4D 2.0's slogan as "don't fight the poor". Where 1.0 imposed pre-existing designs and expected the poor to adapt to them, 2.0 designs around the specific resources, capacities and demands of the poor. Or, we can transform "the network is the platform" to argue that while ICT4D 1.0 saw ICTs as a tool for development, the second phase sees ICTs as the platform for development.

Alternatively, we could break things down into a chronology of ICT4D issues, as represented in Figure 3:

- Readiness: do we have the policies and infrastructure to make ICT availability possible?

- Availability: how can we roll-out ICTs to the poor to help them become users?

- Uptake: in what ways can we implement and apply ICT to make it useful?

- Impact: how can we use ICTs to make the greatest developmental impact?

Figure 3: Changing ICT4D Issues Over Time

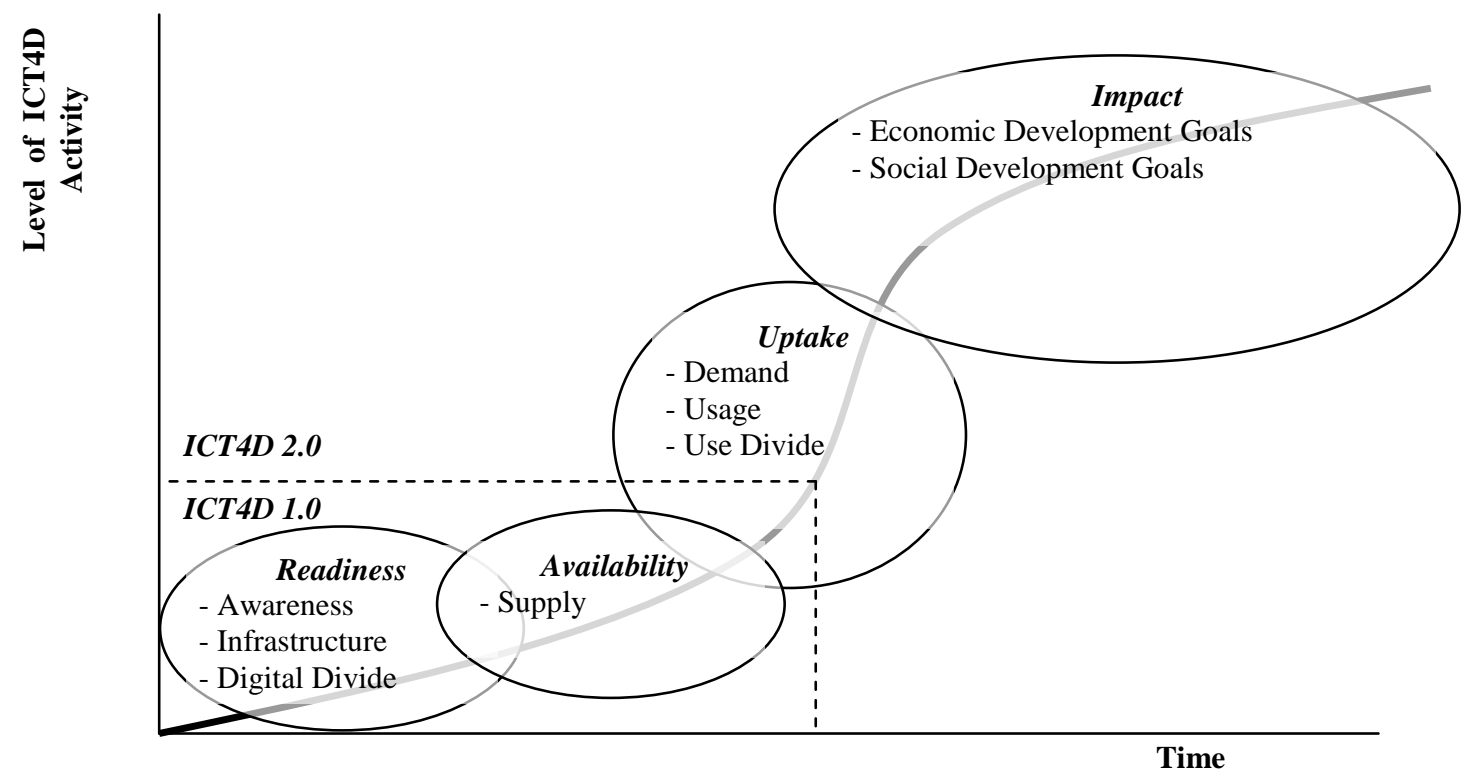

Of course, readiness and availability and uptake issues will remain relevant for at least a generation; probably forever as new waves of technology emerge. And they present ongoing needs for innovation in infrastructure, hardware and software. But mobiles are already a reality, and Internet-connected PCs are a growing possibility, 
particularly for the urban and peri-urban poor. So, where ICT4D 1.0 was about getting the foundations in place, and proof of concept such as piloting largely supplybased uptake, ICT4D 2.0 can turn part of its attention elsewhere.

It can stop thinking solely about pilots, and can instead think more about sustainability, scalability and impact. It can stop thinking from a mono-disciplinary perspective, and can instead think more from a tri-disciplinary perspective that combines computer science, information systems and development studies. And it can stop thinking solely about "needs" - often defined from outside poor communities in rather paternalistic terms. Instead, it can also think about "wants" - what is it that the poor themselves actually demand? How do and would poor communities use digital technologies if left to their own devices?

In conclusion and above all, we can see that ICT4D 2.0 is about reframing the poor. Where ICT4D 1.0 marginalised them, allowing a supply-driven focus, ICT4D 2.0 centralises them, creating a demand-driven focus. Where ICT4D 1.0 - fortified by the "bottom of the pyramid" concept - characterised them largely as passive consumers, ICT4D 2.0 sees the poor as active producers and active innovators. Three overarching questions for this next phase therefore emerge. How can the poor be producers of digital content and services? How can they create new incomes and job through ICTs? And how can we recognise and scale the ICT-based innovations they produce?

\footnotetext{
${ }^{1}$ ITU, Measuring Village ICT in Sub-Saharan Africa, International Telecommunication Union, Geneva, 2007. http://www.itu.int/ITU-D/ict/statistics/material/Africa_Village_ICT_2007.pdf ${ }^{2}$ ibid.

${ }^{3}$ T. Kelly, Beyond the three billion mark, Mobile Phones and Development, ID21 Insights, no.69, 2007, p4. http://www.id21.org/insights/insights69/insights69.pdf

${ }^{13}$ R. Heeks, Implementing and Management eGovernment, Sage, London, 2006.
} 